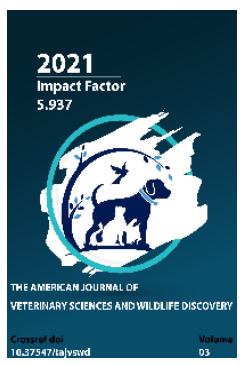

Journal Website: https://theamericanjou rnals.com/index.php/ta jvswd

Copyright: Original content from this work may be used under the terms of the creative commons attributes 4.0 licence.

\section{Efficiency Of Using Domestic Feed Additive On Biological And Physiological Indicators Of Rabbits}

\author{
K. I. Khidirov \\ Republican Rabbit Breeding And Genetic Center, Uzbekistan \\ G. J. Kutlieva \\ Institute Of Microbiology Of The Academy Of Sciences Of The Republic Of Uzbekistan \\ B. I. Turaeva \\ Institute Of Microbiology Of The Academy Of Sciences Of The Republic Of Uzbekistan \\ N. A. Elova \\ Institute Of Microbiology Of The Academy Of Sciences Of The Republic Of Uzbekistan \\ D.K. Nurmukhamedova \\ Institute Of Microbiology Of The Academy Of Sciences Of The Republic Of Uzbekistan \\ Kh.F. Kamalova \\ Institute Of Microbiology Of The Academy Of Sciences Of The Republic Of Uzbekistan
}

\title{
ABSTRACT
}

Research has been carried out to study the influence of "ProBioKorm Uz", a biologically active feed additive, on the development and physiological characteristics of rabbits of 'New Zealand' breed. During the experiment, 2 experimental and a control groups were formed. Adding "ProBioKorm Uz" to the main feed at the rate of $1 \%$ and $2 \%$ had an increase in experimental group rabbits' live weight. Average live weight of them was higher by $5,7 \%-3.8 \%$ than in the control group. Feed units composed $1.59 \%$, dry matter $0.56 \mathrm{~kg}$ (3.61\%) and crude protein $0.11 \mathrm{~kg}$ (3.59\%) compared with the control group. Rabbits of experimental groups had higher indicators of erythrocytes concentration by 0.34-1.00 1012/l (10.34-19.53\%), leukocytes - by 0.370-0.46 109/l (5.66-8, 06\%), as well as a high level of hemoglobin by 7.42-11.08 g/l (6.81-10.08\%) and total protein - by 2.40-4.48 (3.64-6, 42\%).

\section{KEYWORDS}

«ProBioKorm Uz» feed additive, rabbits, probiotics, feed unit, diet crude protein.

\section{INTRODUCTION}

Increasing production of high-quality livestock products is one of the most important tasks of agriculture in Uzbekistan that can only be solved through the development of all industries, including such as rabbit breeding. Due to rabbits' early maturity and high 
intensity of reproduction, one can get a significant amount of dietary meat, skin and fluff in a short period of time. Rabbit meat is a nutritious dietary product, it is tasty, nutritious and well absorbed by a human body, as well as it does not cause allergies. Due to its high protein content and easy digestibility (90\% versus $62 \%$ of best beef varieties), it is especially useful for children, pregnant and lactating mothers, as well as people with digestive problems. In recent years, rabbit farms are being developed on private farms in many regions of Uzbekistan. Meanwhile, concentration of a large number of rabbits in a limited area creates the danger of spread of infectious and invasive diseases. Therefore, it is necessary to introduce probiotics to restore the normal flora.

As it is known, probiotics show high enzymatic activity, regulate and stimulate digestion, while having anti-allergic and anti-toxic effect. They can be divided into five groups: probiotics, prebiotics, synbiotics, bacterial preparations with selective antagonistic activity, and food (animal feed) with probiotics [1,2,3]. In addition, probiotics can reduce fermentation processes and reduce toxicity of metabolites [4].

Use of antibiotics leads to bacteria become resistant to these drugs. Accordingly, use of probiotics or prebiotics in feed enhances growth and positively modulates the immune response in poultry feed compared to antibiotics [5].

At the same time, use of B.coagulans in animal husbandry regulates the balance of intestinal microbiota, promotes metabolism and utilization of nutrients, increase of immunity, as well as resistance to high temperatures, acids and bile [6]. Probiotic effect in prevention of diseases depends on the age of an animal.
Strains with high enzymatic activity are suitable for swine producers as they promote feed digestion and improves indicators of growth [7]. Inclusion and use of CRISPR-Cas nucleases for manufacturing antimicrobial preparations allows development of probiotics with the help transplant fecal microbiome among such animals with one-dimensional stomach as chicken [8].

Two feeding trials were carried out on raccoon dogs and foxes. Mixed probiotic preparation consisting of Bifidobacterium bifidum, Clostridium butyricum, Bacillus subtilis and Bacillus licheniformis was fed to two breeds of dogs. Body weight of raccoon dogs increased due to inclusion of mixed probiotics, whereas foxes' body weight remained unchanged [9].

The effect of Clostridium butyricum and Enterococcus faecalis bacteria (probiotics) on piglets have also been studied. Weaning pigs received a basic diet and a basic diet supplemented with $6 \times 109$ CFU of C.butyricum per $\mathrm{kg}$ and $2 \times 1010 \mathrm{CFU}$ of E. faecalis per kg respectively. Probiotics increased piglet final body weight, average daily weight gain and feed conversion rate, as well as reduced diarrhea. Piglets receiving probiotics had their serum immunoglobulin (Ig) $M$ levels increased on Day 14 and IgA, IgG and IgM levels on Day 28 compared with control pigs [10].

Research has been carried out on influence and effectiveness of probiotic commercial preparations on the productivity of calves. Calves receiving probiotics showed increased mean daily body weight gain (ADG) from birth to weaning (difference $[M D]=83.14 \mathrm{~g} /$ day, $95 \%$ $\mathrm{Cl}=58.36-107.91, \mathrm{P}<0.001)$ by compared to calves on a control diet. Feed conversion ratio (FCR) was lower in calves being fed with probiotics (MD $=-0.13 \mathrm{~kg})$ [11]. 
Research at defining of the effect of the use of Bifidobacterium spp. and Lactobacillus casei probiotics as an alternative stimulants growth of antibiotics for improving chickens growth. Results have shown that adding $0.5 \%$ Bifidobacterium spp. and probiotics L. casei may be a replacement of antibiotics and increases the weight of the eggs, the efficiency of feed and productivity of chickens, and illustrate results of the most profitable business-analysis [12].

Determination of quantitative composition of microorganisms in the contents of large intestine of rabbits rendered the amount of lactic acid bacteria (lactobacilli) in the samples of the first and second experimental groups was $6,8 \pm 0,249(p \geq 0,01)$ and $6.6 \pm 0.306 \mathrm{lg}$ CFU/d, more by 15 and $12 \%$ than in the samples of the control group, and bifidobacteria - $6.3 \pm$ 0.3 and $6.5 \pm 0.167 \mathrm{lg}$ CFU/g, which is more than the control one by 11 and $14 \%$ respectively [13].

Today, due to the relevance of the problem, the aim of the research is to evaluate the effect of a new fodder probiotic supplements «ProBioKorm Uz» consisting of Lactobacillus plantarum, L.casei, L.rhamnosus, Bacillus subtilis, Bifidobacterium, Propionibacterium bacteria strains and Saccharomyces cerevisiae yeasts on the physiological and basic biological indicators of New Zealand breed rabbits.

\section{EXPERIMENTAL PART}

Scientific-commercial experiments were conducted during the period from 2020 to 2021 in the laboratory "Microbiology and biotechnology of probiotics" at the Institute of Microbiology of Academy of Sciences of the Republic of Uzbekistan together with Rabbit Breeding Genetic Center of Uzbekistan. The effect of the new probiotic feed additive "ProBioKorm Uz" was studied in production conditions, as well as immunobiological status of the rabbit organism during intensive rearing. Scientific-commercial research and laboratory analysis of hematological, immunological, biochemical indicators of blood, rate of rabbit growth and safety when using the additive «ProBioKorm Uz» were also studied. In laboratory experiments rabbits' live weight was determined according to hematological and biochemical indexes [15].

Nitrogen (in $\mathrm{mg} / \mathrm{g}$ ) rate is determined by the formula "amount of alkali $\times 1.4 \times 100 /$ amount of sample". Volume of ammonia determined by titration with alkali, it was established total nitrogen amount, multiplying by 6.25 coefficient and thus content of crude protein in the sample was established [16].

Dry matter was determined according to GOST31640-2012 "Feed. Methods for determination of dry matter" standard. A two-stage sample drying method was used. Samples were weighed in 10 and $20 \mathrm{~g}$ each and dried at $65 \mathrm{C}$ to constant weight. To determine hygroscopic humidity, all samples were re-dried in a thermostat at a temperature of $105 \mathrm{C}$ and weighed [ 7].

\section{RESULTS AND DISCUSSION}

The study was carried out on the basis of the Rabbit Breeding Genetic Center of the Republic of Uzbekistan. The object of the study were Nez Zealand breed rabbits at the age of 45 days. Maintenance and feeding of rabbits was carried out in accordance with zoohygienic and zootechnical norms. For research purposes, animals were divided into 3 experimental groups of 25 rabbits each. The first group was the control group and received basic ration consisting of compound feed and herb hay. For rabbits of the second experimental group, in addition to the main diet, "ProBioKorm Uz" 
additive was added at a dose of $1 \%$ of the mass of the mixed feed, for the third group - $2 \%$ of the mass of the mixed feed ( Scheme 1).

Group I - control without the use of a probiotic;

Group II - with the addition of the probiotic feed additive ProBioKorm Uz to the main diet in the amount of $1 \%$.

Group III - with the addition to the basic diet probiotic feed additive ProBioKorm $\mathrm{Uz}$ in the amount of $2 \%$.

To study the dynamics of growth and development of experimental rabbits, weighing was carried out every 15 days in the morning before feeding. According to weighing data, the absolute and average daily gain in live weight was calculated; animals ate the compound feed without residues. At the same time, the studied feed additive " ProBioKorm Uz " had a positive effect on the growth and development of rabbits. Throughout the entire experiment, the highest indicators of live weight were observed in Group III rabbits, which received compound feed with the addition of ProBioKorm Uz at a concentration of $2 \%$ of feed weight.

In the beginning of the experiment after 15 days, 60-days-old rabbits' weight gain in Group II was $5.65 \mathrm{~g}$ and $16,65 \mathrm{~g}$ compared to the control group without additives. At 75th day, the most live weight was observed in the third experimental group - $25.0 \mathrm{~g}$, that was $5.77 \%$ compared to control. Starting from day 90, a dynamic increase in live weight was observed, so an increase was observed in two experimental groups. At the same time, a significant increase was noted in the 3 rd experimental variant - here live weight gain increased by $49 \mathrm{~g}$ (1.97\%). At 105th day of experiments, 2nd test group had an increase in weight of live to $50 \mathrm{~g}(1.71 \%)$, and 3 rd group - 69 g (2.36\%), while control group added to the weight $2.93 \mathrm{~g}$. At the end of the experiment, at 150-days-old, rabbits of the 3 rd experimental group also had the highest live weight by 3.82\% higher than in the control variant (Table 1). Use of the additive led to an increase of live weight gain of experimental group - with average live weight higher than the control group at the 5 , $7 \%-3.8 \%$ rate.

Table 1

Dynamics of rabbits' live weight absolute increase, $g / \%(M \pm m)$

\begin{tabular}{|c|c|c|c|}
\hline Age of rabbits in days & Control group & \multicolumn{2}{|c|}{ Experiment groups } \\
\cline { 2 - 4 } & I & II & III \\
\hline 60 & 4.35 & $10 \mathrm{~g}(2.30 \%)$, & $21(1.02 \%)$ \\
\hline 75 & 2.04 & $18(0.88 \%)$ & $25(5.77 \%)$ \\
\hline 90 & 2.48 & $35(1.41 \%)$ & $49,(1.97 \%)$ \\
\hline 105 & 2.93 & $50(1.71 \%)$ & $69(2.36 \%)$ \\
\hline 120 & 3.25 & $64(1.97 \%)$ & $96(2.97 \%)$ \\
\hline 135 & 3.45 & $75(2.17 \%)$ & $113(3.26 \%)$ \\
\hline 150 & 3.62 & $93(2.57 \%)$ & $138(3.82 \%)$ \\
\hline
\end{tabular}


The study of the dynamics of the average daily increase rabbit live weight showed that experimental groups in terms of average daily gain exceeded control group at the age of 105 days - by 1.0-1.3 $\mathrm{g}(3.37-4.39 \%)$, and at the age of 150 days - by 0.6-1.1 $\mathrm{g}$ (5.5-10.09\%).

Nutritional analysis, which includes determination of dry matter and crude protein, makes it possible to assess the quality of raw materials and serves as the basis for calculating rations. This analysis should primarily be carried out regularly for basic diet feed. As it is well-known, dry matter includes both inorganic and organic components - crude protein, carbohydrates, which together determine fodder quality.

Table 2

Biochemical indicators of feed prepared with "ProBioKorm Uz" feed additive, \%

\begin{tabular}{|c|c|c|c|}
\hline \multirow{2}{*}{ Indicators } & \multicolumn{3}{|c|}{ Groups } \\
\cline { 2 - 4 } & Control & Il experimental & III experimental \\
\hline feed units & 20,7 & $1.59 \%$, & 0.74 units (3.57\%) \\
\hline exchange energy & 19.3 & $3.12 \mathrm{MJ}(1.61 \%)$, & $7.00 \mathrm{MJ}(3.61 \%) ;$ \\
\hline dry matter & 15.5 & $0.25 \mathrm{~kg}(1.61 \%)$, & $0.56 \mathrm{~kg}(3.61 \%) ;$ \\
\hline crude protein & 3.06 & $0.05 \mathrm{~kg}(1.63 \%)$, & $0.11 \mathrm{~kg}(3.59 \%)$ \\
\hline
\end{tabular}

When analyzing nutritional value of feed in the diet of rabbits, it was found that their quality meets the requirements in many respects. Thus, the level of metabolic energy in the prepared feed does not exceed the norm and is $1.61 \%$ in the 3 rd experimental variant (feed unit $-1.59 \%$, dry matter $0.56 \mathrm{~kg}$ (3.61\%) and crude protein $0,11 \mathrm{~kg}$ ), showing an increase of $3.59 \%$ compared to the control one.

As you know, blood is one of internal environment tissues, which is of great importance for the life of an animal organism and due to which metabolism takes place. When studying morphological composition of the blood, experimental group rabbits had higher indicators of the concentration of erythrocytes by 0.34-1.00 1012/l (10.34-19.53\%), leukocytes - by 0.370-0.46 109/l (5, 66-8.06\%), as well as a higher level of hemoglobin by $7.42-$ $11.08 \mathrm{~g} / \mathrm{l}(6.81-10.08 \%)$ and total protein - by 2.40-4.48 (3, 64-6.42\%), which corresponds to a higher level of metabolism in the body, an increase in live weight and increased resistance. Studies have established that morphological and protein composition of the blood of rabbits of all experimental groups was within the physiological norm.

When studying the exterior features of rabbits, it was noted that at the age of 150 days, experimental group rabbits were bigger to their peers in the control group in the length of the body - by 0.5-1.3 cm (0.80-2.10\%), in chest circumference - by 1, 1-1.8 cm (3.00-4.91\%), and according to the downside - down index - by 1.31-1.66\%. Changes in body build indices were noted in 150-days-old rabbits of experimental group II and amounted to 1.31\% (P 0.01) over the peers of the control group, making up $1.66 \%$ ( $P$ 0.001) in the third group.

In conclusion, we can state that the use of "ProBioKorm Uz" feed additive in New Zealand breed rabbits' diet at concentrations of 1 and $2 \%$ resulted in growth and live weight index increase in experimental groups. The average live weight of rabbits was $5,7 \%-3,8 \%$ more than 
in the control group. Indicators of the nutritional value of the feed additive corresponded to the norms and amounted to: feed units $-1.59 \%$, dry matter $0.56 \mathrm{~kg}$ (3.61\%) and crude protein $0.11 \mathrm{~kg}$ (3.59\%) compared to the control group.

\section{REFERENCES}

1. Nikulnikov V.S. Biotechnology in animal husbandry / V.S. Nikulnikov, V.K. Kretinin. M: Kolos, 2007. p.534.

2. Batanov S. D. Bacell Probiotic and LactAcid prebiotic in the diets of dairy cows / S. D. Batanov, O. Yu. Ushkova // Feeding agricultural animals. - 2013. - No.11, P. 2634.

3. Iskhakova A.R. The use of probiotics in waterfowl cultivation/ A.R. Iskhakova // Agricultural science in innovative development of agro-industrial complex: materials of the international scientificpractical conference in the framework of XXV International specialized exhibition "Agrocomplex-2015", March 17-19, 2015 Ufa: Bashkortostan, 2015. - Part 2, P. 99-102.

4. Jing Wang, Haifeng Ji Influence of Probiotics on Dietary Protein Digestion and Utilization in the Gastrointestinal Tract. 2019; 20 (2): 125-131

5. H.S. Al-Khalaifah. Benefits of probiotics and/or prebiotics for antibiotic-reduced poultry. Poult. Sci. 2018 Nov 1; 97 (11): 3807381.

6. Yuanhao Zhou, Zihan Zeng, Yibin Xu, Jiafu Ying, Baikui Wang, Muhammed Majeed, Shaheen Majeed, Anurag Pande, Weifen Li. Application of Bacillus coagulans in animal husbandry and its underlying mechanisms. Animals (Basel). 2020 Mar 9; 10 (3): 454.

7. Weilan Wang, Michael Gänzle. Toward rational selection criteria for selection of probiotics in pigs. Advanced applied Microbiology. 2019; 107: 83-112.

8. Bruce S.Seal, Djamel Drider, Brian B.Oakley, Harald Brüssow. Microbial-derived products as potential new antimicrobials. Vet. Res. 2018 Jul 31; 49 (1): 66.

9. Yongjia Peng, Qiumei Shi, Yujie Wang, Fan Zhang, Zhixin Ji, Jin Zhang Dietary probiotics with different effects on the composition of fecal microbiota in farmed raccoon dog (Nyctereutes procyonoides) and silver fox (Vulpes vulpes fulva). Comparative Study, BMC Microbiotics. 2019 May 24; 19 (1): 109.

10. Kangli Wang, Guangtian Cao, Haoran Zhang, Qing Li, Caimei Yang. Effects of Clostridium butyricum and Enterococcus faecalis on growth performance, immune function, intestinal morphology, volatile fatty acids and intestinal flora in a piglet model. Food Funct. 2019 Dec 11; 10 (12): 7844-7854.

11. John I.Alawneh, Michelle O.Barreto, Robert J.Moore, Martin Soust, Hulayyil AlHarbi, Ameh S.James, Divya Krishnan, Timothy W.J.Olchowy. Systematic review of an intervention: the use of probiotics to improve health and productivity of calves. Prev. Vet. Med. 2020.183: 105147.

12. Ibrahim F.Rehan, Mohammed Youssef, Mootaz A.M. Abdel-Rahman Sohaila. The Impact of probiotics and egg yolk IgY on behavior and blood parameters in a broiler immune stress model front. Vet. Sci. 2020 Apr 9; 7: 145.

13. Omelchenko N.N. Microbiocenosis of the gastrointestinal tract of rabbits when using "Bacell-M" probiotic feed additive / N.N. Omelchenko, I.M. Kaloshkina, A.A. Lysenko // Veterinary of Kuban. - 2017. - No. 1. - P. 1729. 107. 
14. Kondrakhin I.P. Methods of veterinary clinical laboratory diagnostics: Handbook Moscow: Kolos, 2004. 520 p.

15. Preclinical research reference book. Physiological, biochemical and biometric indicators of experimental animals St. Petersburg. 2013. p.110.

16. Feed. Compound feed. Compound feed raw materials. Methods for determination of nitrogen and crude protein content. GOST 134964-93. Russian State Committee for Standards, 1993.

17. Feed. Methods for the determination of dry matter. GOST 31640-2012. Russian State Committee for Standards. Moscow, 2012.

18. Omelchenko N.N. Morphological, immunological and biochemical parameters of the blood of rabbits when using "Bacell-M" probiotic additive / N. N. Omelchenko // Veterinary of Kuban. - 2015. - No. 4. - P. 25-28. 108. 